\title{
Cambio académico. Los grados universitarios. De la escolástica a los primeros ensayos decimonónicos
}

Armando Pavón-Romero, Yolanda Blasco-Gil y Luis-Enrique Aragón-Mijangos

\begin{abstract}
Resumen
En este trabajo analizamos las transformaciones experimentadas en el contenido académico de los grados universitarios a lo largo de la historia. Partimos del modelo medieval europeo para conocer el sentido original de los grados. Utilizamos, luego, el caso mexicano para seguir los cambios. Veremos cómo el significado docente y corporativo de los grados académicos se fue perdiendo y, en su lugar, ganó importancia la adquisición de conocimientos para el ejercicio profesional. El trabajo termina en 1854-1855, con el Plan de estudios que concibe, por primera vez y de manera estructurada, un sistema educativo, en el que todos los grados están escolarizados, requieren para su obtención aprobar exámenes y, en el caso del doctorado, se necesita presentar además una memoria de investigación.
\end{abstract}

Palabras clave: historia, educación, grados académicos, universidad, México, Iberoamérica, España.

Mexicano. Doctor en Historia por la Universidad de Valencia, España. Investigador Titular del Instituto de Investigaciones sobre la Universidad y la Educación (IISUE) de la Universidad Nacional Autónoma de México (UNAM). Temas de investigación: historia social de las universidades hispánicas en la época moderna, en especial, la historia de la Universidad de México; catedráticos y graduados de la Universidad de México en el siglo XVI; organización corporativa y gobierno.

Yolanda Blasco-Gil

yolanda.blasco@uv.es

Española. Doctora en Historia del derecho por la Universidad de Valencia, España. Profesora Titular de la Universidad de Valencia. Temas de investigación: historia de la universidad española en la época contemporánea; orígenes sociales, trayectorias académicas, ejercicio profesional y participación política del profesorado en la Universidad de Valencia; prohibiciones de cátedras universitarias en el franquismo y el exilio académico republicano; los claustros de la Universidad de Valencia en el siglo XVIII.

Mexicano. Estudió la licenciatura de Historia en la Facultad de Filosofía y Letras (FFyL) de la Universidad Nacional Autónoma de México (UNAM). Secretario académico de la Coordinación de Historia de la FFyL de la UNAM. Temas de investigación: historia de la educación en el siglo XIX, en espacial el Segundo Imperio y el Colegio de San Ildefonso. 


\title{
Mudança acadêmica. Os graus universitários. Da escolástica aos primeiros ensaios do século XIX
}

\section{Resumo}

Neste trabalho analisamos as transformações experimentadas no conteúdo acadêmico dos graus universitários ao longo da história. Partimos do modelo medieval europeu para conhecer o sentido original dos graus. Utilizamos, logo, o caso mexicano para acompanhar estas mudanças. Veremos como o significado docente e corporativo dos graus acadêmicos foi se perdendo e, em seu lugar, ganhou importância a aquisição de conhecimentos para o exercício profissional. O trabalho conclui em 1854-1855, com o plano de estudos que concebe, por vez primeira e de maneira estruturada, um sistema de ensino no qual todos os graus são escolarizados, requerem para sua obtenção aprovar exames e, no caso do doutorado, precisa-se apresentar, além disto, uma memória de investigação.

Palavras chave: história, educação, graus acadêmicos, universidade, México, Ibero-américa, Espanha.

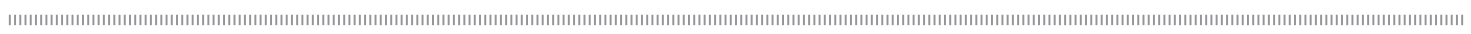

Academic change. University degrees. From scholasticism to the first essays in the nineteenth century

\begin{abstract}
We analyzed the transformation of the academic content of university degrees in history and chose the medieval European model as a starting point to learn about the original meaning of the degrees. Subsequently we used the Mexican model to follow-up on the changes and we will see how the academic and corporate meaning of the academic degrees changed over time and the acquisition of knowledge gained importance for the professional practice. The work ends in 1854-1855, with the first structured curriculum conceived by an educational system that includes schooling of all grades, requests passing of exams and in the case of $\mathrm{PhDs}$ calls for the submittal of a research report.
\end{abstract}

Key words: history, education, academic degrees, university, Mexico, Latin America, Spain.

Recepción: 16/07/13. Aprobación: 20/08/13. 


\section{Introducción}

Los grados académicos de bachiller, licenciado, maestro y doctor han existido en las universidades desde sus orígenes medievales hasta nuestros días. Hemos usado las mismas palabras durante siglos, pero su significado y contenido ha cambiado a lo largo del tiempo. Semejantes transformaciones parecen imperceptibles justamente por haber mantenido en uso las mismas palabras. Ser bachiller, licenciado o doctor hace 400 años era algo bien distinto de lo que la misma palabra significa hoy en día. Desafortunadamente, no existen demasiados trabajos que hayan explicado satisfactoriamente las diferentes realidades que designan esos conceptos académicos o el proceso de transformación de un significado a otro. Por el contrario, es frecuente ver estudios de historia de las universidades, de historia de la educación o de otros campos disciplinares dedicados a temas educativos que no reparan en esta diferencia fundamental y que con cierta facilidad asumen una relación de continuidad histórica y, por tanto, de contenido, suponiendo que no existen diferencias esenciales entre nuestros doctorados, licenciaturas o bachilleratos actuales y aquellos más antiguos. Incluso, algunos de los estudios que advierten la diferencia no alcanzan a explicarla con profundidad ni con precisión. En buena medida, estos trabajos proyectan hacia el pasado nuestros criterios actuales, a pesar de existir, desde hace años, recomendaciones en contra.

Por ello, en este trabajo deseamos abordar algunas de las modificaciones que hemos detectado en el significado y contenido de los grados académicos. Para realizar esta tarea es necesario partir de un punto de referencia. Así, aunque nuestro trabajo está centrado en el caso mexicano, en el tránsito del periodo colonial al independiente, es imposible comprenderlo sin tener claro el significado medieval europeo de los grados académicos. Con esta referencia podemos comprender sobre qué base se operó la transformación y, también, porqué consideramos que el contraste, entre ese sentido original y el último que abordamos, es tan fuerte y notorio que facilita la comprensión del proceso de cambio académico que investigamos.

El objetivo es mostrar cómo el modelo medieval, que concedía un significado docente y corporativo a los grados académicos, se fue perdiendo y la manera en que surgió un modelo nuevo, más cercano al nuestro, en el que se valora, sobre todo, la adquisición y generación de conocimientos para distintos fines, entre ellos y de manera especial, el ejercicio profesional y la investigación científica. El primer apartado, por tanto, no es un panorama general histórico, pretende, por el contrario, establecer los conceptos de referencia sobre los cuales se operarán los cambios que analizaremos en los siguientes apartados. Ni la documentación ni la legislación de la época se ocupaban de definir el significado de cada grado, era algo sabido que daban por supuesto. En cambio, sí proporcionan los requisitos necesarios para obtener los grados académicos. Así, es necesario cotejar esta documentación con aquella historiografía que nos permita comprender la razón de tales requisitos. El libro de Rashdall, The universities of Europe in the middle agges (1997, vol. 1), en este caso y a pesar de su antigüedad, es el más apropiado.

Una vez definidos los conceptos de referencia es posible analizar, en los siguientes apartados, sus transformaciones históricas, que revelarán el advenimiento del modelo educativo contemporáneo. El mejor instrumento para seguir estas transformaciones es la legislación universitaria, novohispana y, luego, mexicana. En los diferentes cuerpos legislativos, decretos y planes de estudio puede percibirse la manera en que están transformándose las concepciones educativas, del sentido escolástico original al contemporáneo, si bien éste apenas queda bosquejado en los diferentes ensayos de la primera mitad el siglo XIX. 
Estos modelos, sin embargo, no están en igualdad de condiciones, más bien advertiremos cómo el antiguo se va transformando para dar lugar al nuevo. De tal forma que en un lapso de treinta años —entre 1824 y 1855 - se conformó, por primera vez y de manera estructurada, un sistema educativo, con diferentes niveles. Ésta será la principal transformación educativa que advertiremos, pues en las épocas medieval y moderna no existían sistema ni niveles educativos. En aquellos periodos las instituciones educativas estaban más bien desarticuladas entre sí y podían impartir, a la vez, lo que hoy consideramos educación elemental junto a lo que también hoy consideramos educación superior. Vale la pena señalar que quizás sea éste uno de los principales errores de los estudios contemporáneos que suelen proyectar nuestro concepto de "educación superior" a unas épocas en que tal no existía, ni en Europa ni en la Nueva España. Si bien ésta es la principal aportación del siglo XIX al ámbito educativo, al profundizar un poco más encontraremos mayores modificaciones. En el terreno de los grados académicos, como podremos ver, también se operó un cambio fundamental, a saber - y a riesgo de adelantar un poco los resultados de este trabajo-, la exclusión del grado de bachiller del espacio universitario, la escolarización de los grados de licenciado y doctor, y la introducción del examen como instrumento para medir la adquisición de conocimientos. Ninguna de estas características era común en el mundo universitario medieval ni novohispano. Por tanto, en esta nueva organización los grados académicos adquirieron un carácter radicalmente diferente del que tuvieron en el mundo escolástico. Ésta es, en nuestra opinión, la aportación del presente trabajo, pues hasta donde hemos podido revisar - y no es éste el lugar para ofrecer el balance historiográfico - no existe un trabajo semejante para el caso mexicano.
Nuestras fuentes son, en su mayoría, legislativas; por tanto, nuestro trabajo tiene un alcance que necesita ser definido, pues no consideramos que en este nivel de análisis se trate de fuentes secundarias. Bien sabemos que la ley expresa un "deber ser" que no tiene, necesariamente, una aplicación directa en la práctica. Por tanto, no se debe confundir la norma con la realidad. Sin embargo, desde otra perspectiva de análisis, la ley también es una manifestación de la realidad social (Peset et al., 2000: 11-42 y Peset, 2012: 321-347). Las investigaciones que hemos realizado sobre historia de las universidades (Pavón, 2010; Blasco, 2000; Blasco y Mancebo, 2010), en las que con frecuencia debemos cotejar los estatutos, constituciones y reglamentos universitarios con las prácticas cotidianas, asentadas en los materiales de archivo, nos revelan que detrás de la norma se encuentran, casi siempre, distintas ideas y posturas que con frecuencia son resultado, o bien de negociaciones o bien de predominio de alguna de las partes que concurren en su elaboración. A veces, la ley da cuenta o sanciona prácticas previamente establecidas; en otras ocasiones, pretende modificar esas prácticas e introducir unas nuevas. En este sentido, el estudio de diversos y sucesivos cuerpos legislativos nos permite ver aquello que ya no existe, que ha desaparecido, así como las novedades que intentan modificar antiguas prácticas. Los autores de la ley, por tanto, no siempre concurren de manera armónica, a veces los conflictos son tales que ninguna de las partes puede imponer su perspectiva y los resultados pueden ser imprevistos.

Para este trabajo es de especial importancia destacar que las diferentes leyes revisadas, sean de gobiernos liberales o conservadores, expresan ideas novedosas, que procuran transformar la organización educativa universitaria novohispana. A veces lo hacen de manera radical, y otras procuran recuperar el modelo antiguo, pero para dotarlo de un nuevo significado, siempre novedoso. Es aquí 
cuando suelen ocurrir las confusiones y es aquí cuando pondremos especial atención, "universidad", "bachiller", "licenciado" o "doctor" no remitirán ya a los antiguos conceptos. Sin duda, en este artículo nos alejamos de la caracterización tradicional de la universidad mexicana decimonónica que ha visto, en esa institución, un espacio más del conflicto entre liberales y conservadores, sin reparar apenas en las transformaciones propiamente académicas. Nosotros hemos procurado centrar el análisis en los cambios académicos de los grados universitarios, donde el conflicto político también se diluye notablemente. Como veremos, el desarrollo de las transformaciones no es lineal o progresivo y en ello radica también el interés de este estudio.

En este trabajo las leyes y planes de estudio analizados adquieren un carácter fundamental pues expresan las nuevas ideas e intereses educativos. Por tanto, estamos realizando una historia de las concepciones de los grados académicos y, en cierto modo, de la universidad misma. Pero a diferencia de lo que sería el pensamiento de un intelectual o de un educador, plasmado en un ensayo, el recurso de las fuentes jurídicas nos pone en el nivel de las ideas y pensamientos de individuos con poder político, con capacidad de instrumentar sus planes. Se trata de ideas que en mayor o menor grado afectarán a individuos e instituciones que deberán sujetarse a lo normado. Por tanto, las ideas expresadas en la ley tienen un valor diferente a las del texto académico. Sin embargo, no es nuestro propósito medir el grado de aplicación de tales pensamientos, pues algunas de estas leyes tuvieron una existencia tan corta que no pudieron instrumentarse. Intentamos, más bien, poner de relieve el surgimiento y transformación de ciertas ideas, en materia de grados universitarios, que terminaron por dejar atrás el modelo escolástico colonial y construir un nuevo sistema educativo, contemporáneo.

\section{Significado docente y corporativo de los grados académicos en la escolástica}

Los primeros datos que debemos considerar para entender el modelo universitario medieval es que antes que instituciones de enseñanza, las universidades nacen como gremios. Es decir, como asociaciones de individuos con intereses comunes, cuyo propósito es la obtención y defensa de privilegios, así como el control monopólico de un bien. En este sentido, los sujetos de las primeras universidades pueden ser los estudiantes o los maestros. La Universidad de Bolonia nace como un gremio de estudiantes, en tanto que la de París surge de la asociación del profesorado (Rashdall, 1997, vol. 1: 1-320).

El objetivo de las universidades medievales, más que la enseñanza, es la formación de profesores (y podemos usar cualquiera de sus sinónimos, tales como enseñantes, catedráticos, maestros, docentes o doctores). Así pues, más que abogados, la universidad medieval formaba catedráticos de derecho; más que médicos, formaba catedráticos de medicina... En este sentido, las universidades medievales se parecen a nuestras modernas "Normales", en tanto que centros educativos para la formación del profesorado. La comparación nos obliga a reflexionar en que hoy tenemos centros de formación del magisterio que se hacen cargo de los niveles educativos elementales y, acaso, medios, pero no es común contar con instituciones de formación para el profesorado universitario. La comparación también resulta, en la actualidad, un poco incómoda para numerosos universitarios, pues ahora las alternativas profesionales son mucho más variadas y la docencia universitaria es apenas una y no necesariamente la más prestigiosa. Este aspecto, el ejercicio profesional, era el que en buena medida estaba en juego a la hora de definir el alcance de los estudios universitarios y, por ello, su restricción al ámbito del magisterio universitario. ¿En 
manos de quién quedaba la autorización del resto de posibilidades profesionales? Debemos contestar que quedaba en manos de otras instituciones. Por ejemplo, para que un bachiller en medicina o derecho pudiera ejercer como médico o como abogado necesitaba un permiso de autoridades no universitarias. El ejercicio de la medicina, en muchas ciudades medievales, era autorizado por los gobiernos municipales o, en el caso novohispano, por el tribunal del protomedicato (Lanning, 1997), y el del derecho lo autorizaban diferentes tribunales o juzgados.

El monopolio universitario era, entonces, la formación de catedráticos y la expresión material de dicha formación era el grado académico. En este sentido podemos decir dos cosas. La primera es que, desde el punto de vista académico, los grados universitarios medievales no acreditan conocimientos; certifican, más bien, distintos aspectos docentes. Es decir, tienen un valor docente. La segunda, que los grados académicos también tienen un valor corporativo, pues llevan aparejados ciertos privilegios, dentro y fuera de la propia universidad. Sólo las universidades pueden otorgar grados académicos, ninguna otra institución educativa puede hacerlo. En las siguientes líneas debemos explicar los significados docente y corporativo de cada uno de los diferentes grados académicos, a saber, bachiller, licenciado y doctor (o maestro).

\section{Sentido docente del grado de bachiller}

El acto que mejor expresa el sentido docente de cualquiera de los grados académicos era aquel con que finalizaba la ceremonia de graduación de un bachiller. En efecto, para terminar aquel acto académico era necesario que el graduando subiera a la cátedra y, desde allí, "en señal de posesión" impartiera su primera lección. Es decir, que hiciera pública su capacidad docente. En casi cualquier acta de grado de bachiller podemos leer un texto semejante al siguiente:

y el dicho señor doctor, respondiéndole con otra oración, le dio y concedió el dicho grado de bachiller en la facultad de artes por suficiencia; concediéndole, asimismo, licencia y facultad para que de hoy en adelante pueda subir y suba en cátedra y exponer la dicha facultad y a los autores de ella; y el dicho Francisco Gudiño fue graduado de bachiller en la dicha facultad por suficiencia y, usando de la dicha licencia y facultad, se subió en la dicha cátedra y, en señal de posesión, comenzó a leer una lección en la dicha facultad que comenzó expetis de expetis agitata est questio utrum ex petri que tq. subycibilis sit predicabilis y, de esta manera, el dicho Francisco Gudiño fue graduado de bachiller en la dicha facultad de artes por suficiencia y por tal hábil y tenido y en el número de los tales contado y numerado. ${ }^{1}$

Este texto nos revela el carácter docente del grado inicial de bachiller, también llamado "grado menor", pues el doctor que estaba concediendo el grado de bachiller daba "licencia y facultad" al graduando para que "de hoy en adelante pueda subir y suba en cáthedra y exponer la dicha facultad y a los autores de ella". Es decir, el doctor que otorgaba el grado no estaba evaluando los conocimientos de un alumno, sino la capacidad de enseñanza; y el nuevo bachiller, "usando de la dicha licencia y facultad, se subió en la dicha cátedra y, en señal de posesión, y comenzó a leer una lección". El nuevo bachiller demuestra que puede ejercer la docencia.

Es cierto que el grado de bachiller era el único para el cual era requisito haber cursado una serie de cátedras. Pero el conocimiento adquirido en aquellos cursos, como acabamos de leer, no era lo

\footnotetext{
${ }^{1}$ Acta del grado de bachiller en artes de Francisco Gudiño, 2 de septiembre de 1578, Archivo General de la Nación (en adelante AGN), Ramo Universidad (en adelante RU), vol. 5, f. 60-60 v. Actualizamos ortografía y puntuación.
} 
que se evaluaba, por parte de los profesores, para conceder el grado menor. Ese conocimiento era necesario para poder enseñarlo y la capacidad de enseñanza era la que se sancionaba al otorgar el grado. En este sentido, el nuevo graduado había dejado de ser estudiante y pasaba a formar parte del grupo de los enseñantes. El bachiller era, según este razonamiento, un catedrático.

Podría decirse que al quedar habilitado para la enseñanza, el bachiller había terminado los estudios. Entonces, es necesario señalar que el grado de bachiller es un grado terminal, equivalente a nuestras actuales licenciaturas y no un grado propedéutico, como lo es hoy en día. También es necesario decir que, por la misma razón, podemos encontrar bachilleres en cualquiera de las facultades existentes en la universidad. Así pues, tendremos bachilleres en artes, en cánones, leyes, medicina y teología.

\section{Sentido docente del grado de licenciado}

El objetivo del grado de licenciado era conseguir la licentia docendi o autorización para enseñar. Es decir, para obtener este grado no era necesario asistir a nuevos cursos, sino realizar prácticas docentes durante un cierto tiempo. A este periodo se le conocía como "pasantía". Los estatutos universitarios novohispanos del oidor Farfán, de 1580, establecían un periodo de cuatro años para todas las facultades, excepto para artistas, a quienes se pedía sólo tres. Es decir, durante un lapso de cuatro o tres años, los bachilleres debían dar clases o, como se decía en la época, "leer lecciones", para ejercitarse y recibir el permiso de enseñanza. Sin embargo, para la época de Farfán el significado de la pasantía se había distorsionado tanto que el oidor permitía la dispensa de años de lectura a cambio de un pago de dinero: por cada año dispensado, "seis pesos de tepusque" (Farfán, 1951: 15. 1 y 2). Semejante conmutación era, sin duda, un extremo de una tendencia que también se experimentaba en las universidades españolas. Clara Ramírez nos informa que en la universidad de Salamanca, sin que el periodo de pasantía se redujera, sí se había reducido el número de lecciones que el aspirante a licenciado debía impartir, al grado de convertirse en un mero trámite. La razón de esta reducción se debía a que los catedráticos de propiedad se oponían a que los pasantes realizaran sus prácticas docentes en los horarios de las clases obligatorias (Ramírez, 2001, vol. I: 295-308).

Jacques Verger, a pesar de explicar el carácter docente del grado de licenciado ha escrito: "paradójicamente esta licentia concedida por el canciller, aunque hubiera garantizado su nivel de capacitación intelectual, no le permitía en absoluto enseñar en la universidad" (Verger, 1994, vol. I: 15). La explicación de semejante paradoja sólo puede explicarse si nos remontamos a los orígenes medievales de la Universidad de París. En efecto, la licentia docendi era concedida por el maestrescuela parisino a todos aquellos profesores cuyos alumnos aspiraban al sacerdocio. Para conceder el permiso, el maestrescuela examinaba previamente a los profesores. Esta licencia es anterior a la creación de la universidad y, de hecho, debido a los conflictos que se suscitaron entre el maestrescuela y los profesores fue que surgió la universidad (Rashdall, 1997, vol. I: 271-320). Sin embargo, al constituirse el grado académico conservó su esencia, la cual es eminentemente docente y eclesiástica: se trataba de un permiso para ejercer la docencia concedido por una autoridad eclesiástica.

Es muy posible que la huella del maestrescuela parisino esté en la base de un funcionario universitario llamado "maestrescuela", "canciller" o "escolástico", que tenía entre sus funciones la gestión y concesión de los grados académicos; más todavía, en universidades como Salamanca o México, el maestrescuela de la catedral era con 
cierta frecuencia el maestrescuela de la universidad (Rodríguez-San Pedro, 1986, vol. I: 381-400; Alonso, 1997: 1-39; Pavón, 2010: 70-74).

Además de las clases que el aspirante a licenciado debía impartir durante el periodo de pasantía, el ceremonial de concesión del grado de licenciado establecía dos actos necesarios. Uno era un examen, otro era la impartición de una lección. El examen ha planteado algunos problemas para los historiadores, pues parece que se trata de una evaluación de conocimientos en una etapa en que ya no se asiste a cursos. Sin embargo, si atendemos al origen parisino de la licentia docendi, podemos sugerir que el objetivo no es tanto la evaluación de los conocimientos del aspirante en sí mismos, sino para su aplicación en la enseñanza, pues es lo que hacía el maestrescuela parisino: ver que los maestros estuvieran en condiciones de enseñar. Podríamos decir, en suma, que la licentia docendi era el reconocimiento eclesiástico de la capacidad de enseñanza del maestro.

\section{Sentido docente y corporativo del grado de doctor}

Una revisión de los libros de grados mayores de la Universidad de México y de los libros en que se asentaba el pago de los derechos por concepto de grados nos revela que para obtener el doctorado no había que hacer más trámites. Ni cursos, como el bachiller; ni pasantía ni práctica docente, como el licenciado. Por tanto, es frecuente ver que poco tiempo después de haber recibido el grado de licenciado podía obtenerse el de doctor, a veces, sólo median días entre uno y otro. Íñigo Carrillo Altamirano, por ejemplo, obtuvo el grado de licenciado en teología el 22 de marzo de 1599 y, al día siguiente, el de doctor. ${ }^{2}$ Ilustrativo también es el caso de García de Carvajal, quien se hizo licenciado en leyes el 13 de diciembre de 1600 y diez días después, el 23 del mismo mes, obtuvo el doctorado en la misma facultad. ${ }^{3}$ El grado de doctor, sin embargo, era el grado mayor por excelencia, el que confería plenos derechos dentro de la universidad. ¿Qué es lo que explica, entonces, esta falta de requisitos académicos y qué es lo que explica su importancia tan alta? El doctorado es, básicamente, un acto de reconocimiento por parte de los otros doctores. Al recibir el grado, el nuevo doctor ingresaba a la corporación de doctores, a la universidad.

Podemos encontrar el origen de este grado también en París, en aquella confrontación entre los maestros de artes y el maestrescuela catedralicio. Rashdall nos cuenta que la licentia docendi era controlada por el maestrescuela parisino, por lo que frente a este espacio de poder, los catedráticos construyeron el suyo propio, en el que ni el maestrescuela ni nadie podía intervenir, sino sólo ellos y era su capacidad para elegir con quién debatir. La recepción de un colega para los debates (la dialéctica medieval) se materializó en la ceremonia de incorporación o "inceptio" (Rashdall, 1997, vol. I: 283-289), por la cual el grupo de profesores recibía en su seno a un nuevo miembro. Así, aunque un profesor tuviera la licentia docendi, si no contaba con la "inceptio", quedaba marginado de una actividad académica fundamental en aquella época. Era, pues, una forma de enfrentar al maestrescuela. Como parte de la ceremonia de "inceptio" se otorgaban al nuevo doctor un birrete, un anillo, un libro abierto, un beso y un abrazo. Son también los elementos que se concedían durante la ceremonia de doctorado, en especial a los clérigos.

Para terminar este apartado podemos decir que el bachiller era un catedrático, el licenciado un catedrático que había recibido la licentia docendi, como reminiscencia del reconocimiento

\footnotetext{
${ }_{2}$ El grado de licenciado en teología, el 22 de marzo de 1600 en AGN, RU, vol, 288, f. 48; y el de doctor en AGN, RU vol. $6, f .302$.

${ }^{3}$ El grado de licenciado en leyes el 13 de diciembre de 1600 en AGN, RU, vol. 288, f. 50 v. y el de doctor, en 23 de diciembre de 1600 en AGN, RU, vol. 288, f. 72 v.-73
} 
eclesiástico y, el doctor, un catedrático que había sido reconocido por sus colegas. Éstos fueron los significados de los grados académicos de la Real Universidad de México, los cuales comenzaron a sufrir una cierta transformación en el siglo XVII, que comentaremos en el apartado siguiente y fueron radicalmente modificados en el siglo XIX, al arribar un nuevo modelo universitario.

\section{Transformaciones académicas de los grados en el siglo XVII}

Los Reyes Católicos, interesados en contar con un gobierno capaz y profesional, hicieron de las universidades los centros de reclutamiento de sus cuadros burocráticos. No es extraño, por tanto, que demostraran mayor interés por las universidades y procuraran intervenir allí donde lo consideraran pertinente. Para ello, en el caso de la monarquía hispánica, los reyes se valieron de "visitadores", funcionarios reales nombrados para determinar el estado de las universidades, que solían estar investidos de capacidad ejecutiva para modificar aquello que juzgaran conveniente (Ramírez, 2001, vol. I: 199-231). Con alguna frecuencia las visitas solían terminar con una nueva normativa universitaria o con cambios importantes a la vigente.

Semejantes acontecimientos tuvieron un efecto sobre los grados académicos universitarios. El acento puesto en la capacidad docente del graduando comenzó a ser desplazado por un interés enfocado en los conocimientos que detentaba el aspirante.

\section{Cambio en la concepción del grado de bachiller}

Para el estudio de esta primera transformación del contenido académico de los grados académicos retomaremos el proyecto de estatutos ordenado por el Marqués de Cerralvo para la Real Universidad de México en 1626. El primer dato a tener en cuenta es sobre los grados de bachiller. La Corona tenía interés por este grado debido a su carácter terminal.
Era el único grado escolarizado y su obtención facilitaba el ejercicio profesional. En el caso de la medicina se trataba, entonces, de un asunto de salud pública. Así pues, el monarca expidió una real pragmática (Fernández, 1953: 115-123) el 4 de noviembre de 1617 , la cual fue recuperada por la comisión redactora de los estatutos universitarios novohispanos de 1626. En el documento podemos leer lo siguiente: "Que por quanto somos informados que en rresevir los estudiantes los grados de bachilleres, que es el de ymportantia, y con [él] se les da licencia para curar... [real pragmática del 4 de noviembre de 1617]" (Cerralvo, 1991: 21. 7).

Se dice que el grado de bachiller "es el de ymportantia" y con ello se produce una profunda transformación en la concepción de los grados académicos. Hasta entonces el grado de bachiller era considerado menor, y los de licenciado y doctor, "mayores". La universidad medieval ponía el acento en el aspecto corporativo, para el cual el doctorado era el grado máximo, el que confería plenos derechos dentro de la universidad. En esa lógica, el grado importante era, por supuesto, el doctorado. En cambio, con la declaración de la real pragmática de 1617 se transfería "la importancia" a la de adquisición de conocimientos. El grado de bachiller era ahora importante porque era el único que se ganaba mediante la asistencia a cursos, donde se adquirían conocimientos. E1 documento, de esta suerte, ya no considera que el bachiller médico es un catedrático de medicina, sino un profesional cuyo objetivo es dedicarse a brindar atención médica.

\section{Cambios en la concepción académica del grado de licenciado}

El carácter docente del grado de licenciado también sufrió un desplazamiento similar al experimentado por el grado menor, pues el acento también fue puesto en la formación académica del aspirante. Hemos comentado ya que en la 
Universidad de Salamanca, las prácticas docentes que debía realizar el aspirante a licenciado se redujeron a una pocas lecciones, debido a que los catedráticos de propiedad impidieron que éstas interfirieran con las horas de clase (Ramírez, 2001, vol. I: 295-308). Por tanto, la pasantía devino un mero trámite y, peor aún, se convirtió en un tiempo de ocio que era de poco provecho para los estudiantes.

La monarquía española decidió entonces que los aspirantes al grado de licenciado dedicaran el tiempo de la pasantía al estudio:

[...] se estatuye y ordena que ningún bachiller de qualquier facultad que sea, que quiera entrar en exsamen secreto para hazerse licenciado en esta universidad, se admita a exsamen asta que conste [...] aver pasado estudiando quatro años después que se hiso bachiller o se pudo hacer (Cerralvo, 1991: 23. 1).

Como es fácil advertir, no se establece que el tiempo de la pasantía debe dedicarse a la práctica docente, sino al estudio. Todavía más, en otro estatuto se añade la necesidad de contar con libros de la facultad: "Y se ofresca a la ymformación sumaria de aver pasado y estudiado y tenido libros, y tenerlos, de la facultad que quiciere rresevir grado" (Cerralvo, 1991: 23. 4).

La transformación en el contenido académico del grado de licenciado no implicó la asistencia a nuevos cursos, pero sí se estableció la normativa de estudiar y tener libros de la facultad. No se pone el acento en el aspecto docente del grado, sino en el escolar, de adquisición de conocimientos.

Para terminar este apartado vale la pena decir que no se advierte una transformación similar en el contenido del doctorado. Pero los cambios detectados en los de bachiller y licenciado demuestran que las monarquías dedicaban un mayor interés a la preparación de los universitarios.

\section{Ensayos de un nuevo modelo educativo en el siglo XIX El fin del monopolio universitario sobre los grados académicos en 1823}

La llegada de la Independencia trajo, casi inmediatamente, cambios en el sentido corporativo y académico de los grados académicos. Desde 1823 y hasta por lo menos 1855 podemos advertir un proceso que modificará profundamente el contenido académico de los grados y que los pondrá en una sintonía más cercana a la nuestra. En estos 32 años se publicaron varias leyes y, mediante su lectura y análisis, podemos advertir el proceso de transformación mencionado.

El primer cambio tuvo lugar en 1823, tras la caída de Agustín de Iturbide. El congreso, mediante un texto breve, publicó un decreto que terminaba con el monopolio universitario de los grados académicos, por lo menos con el grado de bachiller. Leamos el decreto:

E1 soberano Congreso mexicano decreta: Entretanto se sanciona el plan general de estudios, se concede la facultad de establecer cátedras de derecho natural, civil y canónico a todos los colegios de la nación, que no las tengan [...] Asimismo podrán, a excepción de los de México y Guadalajara, conferir cada cual a sus alumnos todos los grados menores adoptando para este efecto los estatutos de las universidades de la nación (Decreto, 1825: 209) ${ }^{4}$

La medida significaba un cambio radical, pues hasta entonces sólo las universidades de México y de Guadalajara detentaban el monopolio de los grados académicos. Todos aquellos alumnos 
que estudiaban en los diferentes colegios novohispanos, si querían ganar el grado de bachiller, tenían que matricularse en alguna de estas dos universidades y posteriormente tramitar el grado menor. La Universidad de México funcionaba, de esta manera, como centro de certificación de la enseñanza impartida por los diferentes colegios. El monopolio universitario comenzaba al levantar la matrícula. En efecto, los estudiantes de los colegios no sólo se inscribían en sus colegios, sino también en la universidad. Para ello y en algunas ciudades como Puebla, Oaxaca y Celaya, la universidad mantenía un "teniente" de secretario que levantaba las matrículas de los colegiales (Becerra, 1963: 127 y Palafox, 1775: XXV. 361). En otras, nos dice Becerra, era un funcionario de cada colegio quien llevaba el registro. Al parecer, también había colegiales que viajaban a la ciudad de México para matricularse. Al terminar los cursos y, para graduarse de bachilleres, tenían que ir a la Universidad de México.

El decreto de 1823 terminaba con el monopolio universitario de los grados de bachiller, pues en adelante los colegios podrían conceder "todos los grados menores", es decir, grados de bachiller en artes, pero también en leyes, cánones, teología e incluso medicina. Semejante autorización abría la oportunidad para los colegios de impartir enseñanzas propias de facultades mayores. Esto quizás no era una novedad para los colegios, pues algunos de ellos, al parecer, impartían clases de derecho y de teología. Por tanto, lo verdaderamente significativo era la posibilidad de conceder el grado académico de bachiller. El congreso, en este sentido, terminaba con aquel monopolio universitario.

\section{La legislación de 1833. Primera supresión de la universidad y de los grados de bachiller y licenciado}

Diez años después, como es bien sabido, el 19 de octubre de 1833, el gobierno dio un paso adelante y decretó la primera supresión de la universidad (Alvarado, 2000: 129-160 y Gómez Farías, 1834a: 1). ${ }^{5}$ En su lugar creó una Dirección General de Instrucción Pública, para el Distrito y Territorios de la Federación (Gómez Farías, 1834a: 2): "La dirección tendrá a su cargo todos los establecimientos públicos de enseñanza, los depósitos de los monumentos de artes, antigüedades e historia natural, los fondos públicos consignados a la enseñanza, y todo lo perteneciente a la instrucción pública pagada por el gobierno (ibid.: 3).

$\mathrm{Y}$, de manera especial para nuestro trabajo, destaca el artículo 8, en el cual se establece que "los grados de doctor que se obtengan en los diferentes establecimientos, serán conferidos en ceremonia pública por la dirección [...]" (Gómez Farías, 1834a: 8).

La Dirección General de Instrucción Pública se haría cargo de "todo lo perteneciente a la instrucción pública pagada por el gobierno". Asimismo, asumía el control de los grados de doctor, conferidos por "los diferentes establecimientos". Esto es, la nueva oficina se hacía cargo de la certificación educativa, hasta entonces en manos de las universidades de México y Guadalajara.

Unos días después, el 23 de octubre, Gómez Farías elaboró otro decreto acerca de los establecimientos de instrucción pública en el Distrito Federal (Gómez Farías, 1834b: 1-34). En este documento puede verse cómo las antiguas facultades eran sustituidas por otras instituciones llamadas "establecimientos". Tres de estos establecimientos corresponden a las antiguas facultades mayores: Jurisprudencia a Cánones y Leyes; Ciencias Eclesiásticas a Teología, y Medicina a la antigua facultad de Medicina. La antigua facultad de artes parece dar lugar al Establecimiento de Estudios ideológicos y humanidades. Además y fuera del

\footnotetext{
${ }^{5}$ Recuérdese que las leyes del 19 y 23 de octubre son de 1833, sin embargo, utilizamos una edición de 1834. El reglamento, que se citará abajo, por otra parte, es de 1834, al igual que la edición que consultamos.
} 
antiguo ámbito universitario, aparecen dos nuevos "establecimientos", uno de ciencias físicas y matemáticas, con lo cual la enseñanza impartida en el Colegio de Minería adquiría el mismo estatuto que las antiguas facultades, y otro de Estudios Preparatorios, el cual y en cierto modo constituía, por primera vez, un nivel propedéutico de los superiores. Sin embargo, ni esta ley ni su reglamento articularon con precisión los niveles educativos, ni la necesidad de cumplir con uno anterior para pasar al siguiente (Gómez Farías, 1834c: 230-233 y 236-237). Se trata, más bien, de un bosquejo que culminará años más tarde.

Puede apreciarse que en ninguno de los dos documentos analizados se habla de otro grado académico que no sea el de doctor. Es decir, parece que desaparecían, junto con la universidad, los grados de bachiller y licenciado. El doctorado vendría a ser terminal y, por tanto, equivalente a nuestros actuales títulos de licenciado:

18. Para obtener el grado de doctor en las facultades mayores que se enseñan en los establecimientos del gobierno, se requiere acreditar haber estudiado todos los cursos de la misma facultad que se den en el establecimiento respectivo, y haber sido aprobado en el examen particular de cada uno de ellos. Se sujetará además el candidato a un catequismo público o examen general de toda la facultad, y leerá en él una disertación que escribirá sobre el punto que le designe la dirección en el término que se señale por regla general, y evaluando este trabajo del modo que dispongan los reglamentos (Gómez Farías, 1834b: 18).

El doctorado, de esta suerte, se transformaba completamente con respecto a su sentido escolástico. Ya no se trataba del ingreso a la corporación de doctores, sino de un certificado de terminación de estudios. Para obtenerlo, como puede leerse, se requería haber cursado todas las cátedras de los planes de estudios, así como haber aprobado los exámenes de cada asignatura. Además, el aspirante debería acreditar un examen general de conocimientos, y presentar una "disertación" escrita. E1 examen, como recurso de acreditación, aparece como un elemento novedoso, pues aunque no era desconocido en la universidad escolástica y colonial, ${ }^{6}$ el elemento de acreditación de cada curso era la asistencia (Cerralvo, 1991: 21. 18). Ahora, en cambio, se aplicaría un examen al final de cada curso, y otro más al término de cada nivel educativo. La disertación final, por su parte, no es una tesis de investigación. Se dice específicamente que deberá tratar un punto señalado y se elaborará en un tiempo determinado (Gómez Farías, 1834b: V. 18). Nos recuerda todavía a las antiguas tesis escolásticas, que se desarrollaban sobre un punto elegido, de entre tres, y se preparaban con 24 horas de anticipación.

Nos encontramos ante una concepción educativa que podríamos llamar "de transición", en la que se está perfilando un nuevo sentido educativo, pero en el que aún persisten algunos aspectos del modelo universitario anterior. Han desaparecido dos grados académicos y se ha mantenido uno, pero su esencia académica ha sido modificada radicalmente. Por su parte, los establecimientos mantendrían el monopolio del doctorado, es decir, el monopolio del grado académico, como lo habían tenido las universidades de México y Guadalajara: "Fuera de los establecimientos

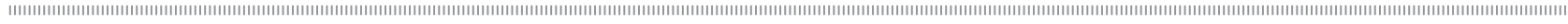

${ }^{6}$ Además del examen que se realizaba para obtener el grado de licenciado y del cual ya se ha hecho mención, en la universidad moderna es posible advertir el nombramiento de examinadores para la facultad de artes, pues existía la posibilidad de obtener el grado bachiller obviando uno de los tres cursos obligatorios. Para ello, había que presentar un examen de suficiencia. Por ello, los grados que se otorgaban de esta manera se llamaban así "bachiller por suficiencia". Para el caso de México puede verse una legislación tan temprana como la de 1580 o el proyecto de 1626 (Farfán, 1951: 13. 2, véase también Cerralvo, 1991: 21. 20).
} 
del gobierno, a que se contrae esta ley, no podrá conferirse ningún grado académico, ni en éstos se conferirá sino el de doctor" (Gómez Farías, 1834b: V. 19).

Este proceso de transición continuará en los siguientes años y no sólo porque la universidad, que ahora había sido suprimida, entraría en un proceso de restauraciones y nuevas supresiones, sino porque el nuevo modelo tardaría todavía unos años en alcanzar una forma acabada.

\section{Restablecimiento del grado de bachiller y de su carácter terminal. El Plan general de estudios de la} República mexicana. Agosto de 1843 Es bien sabido que la legislación de 1833 fue abolida a los pocos meses de haberse publicado (Gómez Farías, 1834d: único) y su valor radica, más bien, en las ideas que expresaba, pues significaban un gran avance con relación a la educación anterior. Así pues, fue restablecida la Universidad, junto con los colegios, y la Dirección General de Instrucción Pública fue sustituida por "una Junta provisional, compuesta por los rectores de los colegios" (O'Gorman, 2009: 8).

Diez años después de aquella legislación, Manuel Baranda, bajo la presidencia de Santa Anna, elaboró un "Plan general de estudios de la República mexicana", el cual se dio a conocer en un decreto de 18 de agosto de 1843. El primer punto a destacar es que los estudios superiores requerirían definitivamente de unos estudios preparatorios. La disposición parece cercana a la de 1833, pero aquí se enuncia para qué carreras y cuánto durarían esos estudios preparatorios (Baranda, 2011: I. 6 y 7).

Las antiguas facultades y los modernos "establecimientos" de 1833 ahora son dejados atrás, y en su lugar se habla ya de "carreras". La referida al derecho se denomina "del foro". El sólo uso de la palabra "foro" nos revela que también ha quedado atrás la concepción universitaria escolástica que ponía el acento en la formación de catedráticos; por fin, ahora parece establecerse la idea de que los estudios superiores tienen por objeto un ejercicio profesional más amplio, en el ejemplo del derecho, el foro (Baranda, 2011: I. 1).

En esta legislación reaparecen los tres grados académicos. Veamos, para comenzar, lo normado para el bachiller:

16. Los cursantes que hubieren obtenido la aprobación en el examen de que habla el artículo 12 [sobre estudios preparatorios], podrán ocurrir a la Universidad respectiva, la que sin otro requisito que la constancia de la aprobación, les expedirá el título de bachiller.

17. Los que hubieren concluido los estudios de cualquiera carrera, y fueren aprobados en el examen general, de que habla el mismo artículo 12, podrán ocurrir a la Universidad respectiva, la que les expedirá el título de bachiller en la carrera que hubieren cursado (Baranda, 2011: I. 16 y 17).

El antiguo grado de bachiller, como puede verse en la cita, se ha transformado en un "título" que se obtiene tras haber aprobado todas las asignaturas del plan de estudios y un examen general. El grado inicial se ha escolarizado totalmente. El bachiller ya no es un catedrático, es un estudiante que ha cursado unas asignaturas y las ha acreditado mediante exámenes. Este grado, sin embargo, conserva, del modelo anterior, su carácter terminal, en tanto que habilita para el ejercicio profesional. El bachiller en esta ley vuelve a ser equivalente a nuestros actuales títulos de licenciatura. En este sentido, podemos decir que se restaura el criterio expresado en el siglo XVII, que hacía del grado de bachiller "el de ymportantia". Es posible que se buscara expresar ese carácter terminal y la habilitación para el ejercicio profesional al utilizar la palabra "título", en lugar de "grado". El título de bachiller, además de ser el certificado 
de terminación de cualquier carrera, también se extendió a los estudios preparatorios. Podríamos decir entonces que el título de bachiller señalaba la terminación de una etapa escolar, bien preparatoria, bien profesional.

$\mathrm{El}$ texto que hemos citado nos revela asimismo que la restauración de la universidad no era una vuelta atrás. Su carácter en este Plan era bien diferente al antiguo, pues aunque se le devolvía el monopolio de los grados, quedaba impedida para solicitar "otro requisito que la constancia de la aprobación”. Es decir, la universidad había quedado reducida a una oficina de expedición de títulos.

Los grados de licenciado y doctor también fueron restablecidos, pero no se explica cómo ganarlos. Sólo se dice que los bachilleres "podrán obtener los grados de licenciado o de doctor en la Universidad a que pertenecen, conforme a los estatutos vigentes". (Baranda, 2011: I. 18). En esta legislación, insistimos, el grado de bachiller, ahora denominado "título", volvía a ser "el de ymportantia", por ello, el desinterés del legislador respecto a los grados de licenciado y doctor.

Podríamos decir que esta normativa dividió el campo en tres grandes bloques: la parte escolarizada, la de certificación y el ejercicio profesional. La acreditación de la primera debía hacerse mediante el cumplimiento del Plan de Estudios, a saber, cursando asignaturas y aprobando exámenes en instituciones ajenas a la universidad. Los objetivos de la enseñanza asimismo se habían ampliado. La transformación de las facultades en "carreras" dejaba atrás la idea exclusiva de formar catedráticos, ahora la enseñanza contemplaba más alternativas profesionales. El segundo aspecto, la certificación de los estudios realizados, se devolvía a la universidad, pero sólo de manera formal, sin capacidad para fijar criterios o requisitos. Por último, la autorización del ejercicio profesional volvió a transferirse a instituciones externas al ámbito de la enseñanza, por ejemplo, los tribunales en el caso del derecho y, para la práctica médica, el colegio de médicos y el consejo de salubridad (Baranda, 2011: I. 23 y 24). Acerca del caso de la abogacía puede leerse: "19. Los que hayan concluido la carrera del foro, inclusa la práctica, pueden recibirse de abogados en cualquiera de los tribunales superiores de la República, en la forma que explican los siguientes artículos" (Baranda, 2011: I. 19).

Sin enseñanza, sin un monopolio efectivo de los grados académicos y sin el control del ejercicio profesional, la restauración de la universidad era una mera formalidad. De hecho, el Plan de Estudios la sustituía mediante dos acciones. Una, transfiriendo la enseñanza a los colegios, que adquirían entonces una nueva condición, dotándolos además de una efectiva capacidad de certificación, y dos, creando la Junta Directiva General de Estudios, la cual tenía entre sus funciones "Cuidar de que en toda la República se observen en la enseñanza, las bases que ordena esta ley, en lo relativo a estudios preparatorios, cursos, exámenes y grados" (Baranda, 2011: VI. 79). Casi nada quedaba del modelo colonial.

\section{Primer sistema educativo y nueva concepción de los grados académicos. Nuevo Plan general de estudios y su Reglamento. 1854-1855}

Una década después, en 1854, Teodosio Lares (Melgar, 1995: 103-124 y Ríos, 2001: 355-385), ministro de justicia, negocios eclesiásticos e instrucción pública, elaboró un nuevo Plan de Estudios, acompañado ahora de su reglamento. Lares fue un ministro que, por lo menos desde 1853 y hasta la caída de Maximiliano en 1867, formó parte de los gobiernos conservadores. Sin embargo, sería difícil sostener que el Plan general de estudios es una propuesta educativa conservadora o regresiva. Por el contrario, se trata de un Plan de estudios que bien puede considerarse contemporáneo. En 
sus páginas puede advertirse, por primera vez, la concepción de un "sistema educativo", organizado en cuatro niveles, de menor a mayor, a saber, instrucción primaria; instrucción secundaria o preparatoria; instrucción superior de facultades, y estudios especiales (Lares, 1877: I. 1). Podemos decir entonces que se trataba de un progreso en materia educativa. Para nuestro estudio son importantes las definiciones acerca de la educación secundaria y superior. Citemos, en primer lugar, la manera en que el Plan definía la educación secundaria: "La instrucción secundaria sirve de preparación para los estudios de facultad" (Lares, 1877: III. 4). Por lo que toca a la educación superior, el plan establecía dos puntos importantes: "14. La instrucción superior de facultades abraza una serie determinada de conocimientos indispensables para ciertas carreras o profesiones sujetas al orden de grados académicos. 15. Las facultades serán cuatro, a saber: Filosofía. Medicina. Jurisprudencia. Teología" (Lares, 1877: IV. 14 y 15).

Además de la división en niveles educativos, el nuevo sistema establecía que para acceder al nivel siguiente era necesario acreditar el anterior; en el caso de la educación superior, los grados académicos, podemos adelantar ahora, también aparecían jerarquizados y, sobre todo, escolarizados.

\section{La enseñanza secundaria y el grado de bachiller en fillosofía. 1854-1855}

A continuación estudiaremos dos aspectos de este Plan: la parte de educación secundaria y la dedicada al grado de bachiller en filosofía. Veremos cómo se encuentran aquí las bases de nuestros modernos bachilleratos y, en buena medida, cómo se generan las confusiones que existen alrededor de la antigua facultad de artes. A nosotros nos interesan estos puntos por el significativo cambio en uno de los grados académicos, el de bachiller en filosofía.

Una vez definida la instrucción secundaria, el Plan fijaba la duración de este nivel educativo en seis años, divididos en dos periodos de tres años cada uno. "El primero se llamará de latinidad y humanidades, y el segundo, de estudios elementales de filosofía" (Lares, 1877: III. 6). Desde la época actual no resulta difícil comprender esta división. Si bien los contenidos han cambiado en la actualidad, los primeros tres años parecen corresponder a nuestra actual secundaria, y los siguientes tres, al bachillerato contemporáneo.

La misma división en dos periodos parece ser una reminiscencia del modelo universitario escolástico, novohispano. En efecto, podría equipararse la primera parte "de latinidad y humanidades" con la necesidad de cursar gramática y retórica latinas antes de ingresar a cualquiera de las facultades. La segunda parte de la educación secundaria parece acercarse a la antigua facultad menor de artes, donde se estudiaba lógica o filosofía. Podríamos establecer otro paralelismo en cuanto que, para estudiar teología y medicina, era necesario cursar primero artes. Es decir, podríamos hablar de cierto carácter propedéutico de la facultad menor, pero debemos tener muy claro que este carácter no trascendía a las otras facultades, las de leyes ni cánones. Además, es necesario recordar que la propia facultad de artes era, en sí misma, terminal, pues ofrecía, como se ha dicho ya, todos los grados, desde el menor de bachiller hasta el mayor de maestro. En este sentido sería difícil asociar la facultad menor del periodo escolástico con la educación secundaria caracterizada en este plan.

Si bien el plan de estudios parece retomar las características de la antigua facultad de artes, se divide en dos niveles (secundaria y superior) y en dos entidades bien diferenciadas. Una de estas dos entidades es la que venimos comentando, correspondiente a la educación secundaria, donde se enseñarían los "estudios elementales de filosofía" y cuyas sedes serían los antiguos colegios, llamados ahora "institutos nacionales" (Lares, 1855: III. 21). La otra entidad, cuyos antecedentes 
podríamos encontrar en la antigua facultad de artes, era la "facultad de filosofía" (Lares, 1877: IV. 15). Ésta se dividiría en tres secciones o carreras, a saber: literatura, ciencias físico-matemáticas y ciencias naturales (Lares, 1877: IV. 17). No cabe duda que las titulaciones de ciencias encontraban sus antecedentes en el antiguo Colegio de Minería $\mathrm{y}$, de hecho, en esas instalaciones se impartirían sus cursos (Lares, 1855: III. 20). Pero se habían integrado a la facultad de filosofía para dotarlas de un rango universitario.

Si continuamos buscando la huella de la vieja facultad menor en el Plan de estudios de 1854, podemos decir que como resultado de la creación de los dos nuevos niveles y de las dos nuevas entidades, los grados académicos también se separaron. Tal fragmentación tuvo como sujeto una de las vertientes del grado de bachiller en filosofía. Antes de proseguir, sin embargo, es necesario explicar que este grado tenía cuatro versiones diferentes. Como ya hemos dicho, había tres secciones o carreras en la facultad de filosofía, por lo que para obtener el grado menor era necesario cubrir diferentes requisitos. De esta suerte, sólo en la facultad de filosofía había, por decirlo así, tres diferentes currículos para hacerse bachiller. Aquel otorgado en la sección de literatura, el concedido en la sección de ciencias físico matemáticas, y el correspondiente a la sección de ciencias naturales. El de la sección de literatura se concedía tras la culminación de los estudios secundarios. Por su parte, las dos secciones de ciencias, para entregar el mismo grado, pusieron la obligación de cursar, además de la instrucción secundaria, dos años en la facultad (Lares, 1877: IV. 20 y 21). La cuarta versión del mismo bachiller en filosofía se derivaba de la facultad de medicina. Esta facultad solicitaba el grado como requisito para las dos carreras que ofrecía, medicina y farmacia. Pero como en el caso de las secciones de ciencias, la facultad de Galeno ponía unos cursos, durante un año, para otorgarlo.

A nosotros nos interesa el bachiller en filosofía de la sección de literatura, pues fue el único que para concederse sólo requería de la culminación de los estudios secundarios. Esto es, el grado parece quedar fuera del ámbito de las facultades, constituyendo así una novedad en la tradición universitaria mexicana:7 "18. Constituirán el primer periodo de los estudios de la facultad de filosofía en la sección de literatura, los correspondientes a instrucción secundaria, concluidos los cuales se podrá aspirar al grado de bachiller" (Lares, 1877: IV. 18).

Es posible argumentar que si bien la separación entre el nivel de secundaria y el de facultad está claramente establecida en el Plan, aún no está del todo acabada, pues para efectos del grado, la última parte de la secundaria es asimilada a la primera de la facultad. En este sentido podemos sugerir que, en efecto, se trata de una situación de transición, en la que están presentes a la vez los criterios antiguos y los contemporáneos. Pero tampoco queda duda que, por primera vez, se está diferenciando enseñanza secundaria de educación superior y que el grado de bachiller en filosofía de la sección de literatura se está convirtiendo en la titulación de la instrucción secundaria. El grado se está alejando del ámbito de las facultades y se está transfiriendo al nivel propio de la educación secundaria. Aquí tenemos, en germen, el "bachillerato" como etapa propedéutica de los estudios superiores (recuérdese que "La instrucción secundaria sirve de

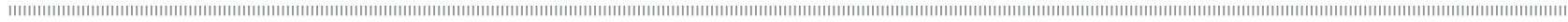

${ }^{7}$ Es posible encontrar un cierto paralelismo en la época colonial, pues numerosos estudiantes de los colegios del virreinato cursaban el curriculum de artes en sus propias escuelas y sólo acudían a la universidad a recibir el grado. Ahora, según el plan de 1854 , los estudiantes cursarían en los colegios o institutos nacionales y acudirían a la universidad para tramitar el grado. La aparente similitud termina al considerar el carácter de los estudios, pues los colegios, aunque no eran "facultades", impartían cursos considerados de facultad, en tanto que ahora sus enseñanzas serían abiertamente de nivel secundario.
} 
preparación para los estudios de facultad"). Como consecuencia, podemos decir que en el Plan de estudios y su Reglamento, el grado menor perderá su antiguo carácter terminal, por lo cual tampoco habilitaría más para el ejercicio profesional. En suma, la titulación de literatura nos resulta relevante porque el plan de estudios había hecho, así fuera de una sola de las versiones del grado de bachiller en filosofía, el instrumento para diferenciar los niveles educativos secundario y superior.

\section{La educación superior y la escolarización de los grados académicos}

Los demás grados académicos también sufrieron una transformación radical, pues todos fueron escolarizados. Es decir, para ganar alguno de los tres grados en cualquiera de las facultades se hizo necesario cursar y acreditar mediante exámenes una serie de asignaturas. Así, se establecía en el Plan de estudios: "Los estudios de cada facultad se dividirán en tres periodos, que corresponderán a tres grados académicos; estos grados son los de bachiller, licenciado y doctor" (Lares, 1877: IV. 16).

El primer dato a tener en cuenta es que, además del grado propedéutico de bachiller en filosofía, cada una de las facultades contará con su propio grado de bachiller, el cual se obtendrá luego de cursar una serie de asignaturas. Encontraremos, de esta manera, bachilleres en jurisprudencia, en medicina y en ciencias eclesiásticas. El siguiente dato a considerar es que, como adelantamos, para ganar cada uno de los grados académicos es necesario cursar una serie de materias durante un cierto número de años. A continuación enunciaremos, de manera breve, los requisitos que se solicitaban, en cada una de las facultades, para obtener los diferentes grados académicos.

La titulación en literatura de la facultad de Filosofía, para el grado de bachiller requería, como hemos mostrado de sobra, únicamente la acreditación de la última etapa de la instrucción secundaria. Luego, si se cursaban dos años más, podía obtenerse el grado de licenciado, y tras un año más de cursos se alcanzaba el doctorado. Para obtener el bachiller en las secciones de ciencias físico-matemáticas y ciencias naturales, se requería, como también ya hemos dicho, dos años de cursos en la facultad. Luego había que seguir dos años más y, entonces, podía obtenerse el grado de licenciado; tras otros dos años más, el doctorado. Es decir, una vez terminados los estudios secundarios, con tres años de cursos podía obtenerse el doctorado en la sección de literatura, pero para ganar el mismo grado en las otras secciones era necesario cursar durante seis años en la facultad.

La carrera de medicina, como ya hemos adelantado, no requería, para su ingreso, de los seis años de estudios secundarios; cinco años eran suficientes. Una vez inscrito en la facultad los cursos duraban ocho años. El primero de ellos servía para obtener el bachiller en filosofía; después había que cursar otros cinco años para hacerse bachiller en medicina. Para este momento se habían hecho ya seis años en la facultad. El grado de licenciado se podía ganar al terminar el séptimo año de estudios y, con el octavo, se concedía el doctorado (Lares, 1877: IV. 23-28).

La otra carrera impartida en la facultad de medicina era farmacia. Tampoco requería los seis años de la instrucción secundaria, con cinco se podía ingresar a la facultad. Allí, los estudios duraban seis años. Los dos primeros eran los mismos que para medicina o, como diríamos hoy, formaban un tronco común. Por tanto, al término del primer año se podía obtener el bachiller en filosofía; con tres años más, el bachiller en farmacia. Acreditado el quinto se podía optar por el grado de licenciado y, con un año más de cursos, se habilitaba para el doctorado (Lares, 1877: IV. 23, 30-35).

Por su parte, para ingresar a la facultad de jurisprudencia era necesario contar con el grado de 
bachiller en la sección de literatura. Luego, para hacerse bachiller, había que cursar cuatro años y, tras otros tres, se podía optar por el grado de licenciado. El doctorado se obtenía tras acreditar el octavo año de estudios. Es necesario decir que el Plan de estudios ofrecía la oportunidad de obtener el bachiller en leyes o bien en cánones. Se trataba, podemos decir, de una reminiscencia de la antigua universidad novohispana. Pero los grados de licenciado y doctor sólo podían hacerse en leyes (Lares, 1877: IV. 37 y 38). Si uno deseaba obtenerlos en cánones había que redirigirse a la facultad de teología (Lares, 1877: IV. 39 y 43).

Finalmente, la última facultad contemplada en el Plan de estudios era la de teología. Para su ingreso era necesario contar con el grado de bachiller en filosofía, en la sección de literatura. Los estudios en esta facultad duraban un total de ocho años. Los primeros cuatro eran suficientes para alcanzar el bachiller en teología. Con tres años más se podía optar por el grado de licenciado. Para entonces, el alumno había cursado siete años y, con el octavo, podía hacerse doctor (Lares, 1877: IV. 42 y 43).

Tras estas líneas queda suficientemente demostrada la transformación de los grados académicos. Todos han sido escolarizados y ya no guardan ninguna relación con los grados de la antigua universidad novohispana. Sin embargo, el Plan de estudios traería algunas otras novedades más que es necesario explicar. Hemos visto ya que cada facultad contaba con su propio grado de bachiller. Pero éste había perdido el carácter terminal, asociado en gran medida al ejercicio profesional, del que había gozado en el periodo colonial. En efecto, en este Plan de estudios, el grado de bachiller sólo es necesario para continuar con los estudios posteriores de licenciado y doctor. Pero el ejercicio profesional se transfiere al grado de licenciado. Si bien resulta interesante que el Plan de estudios sólo se ocupa del ejercicio profesional de las carreras de medicina, farmacia y abogacía (Lares,
1877: IV. 27, 28, 34, 36 y 41), sin tener en cuenta el de las facultades de filosofía ni teología.

Otra de las características del Plan de estudios relativas a los grados académicos es la necesidad de presentar exámenes, no sólo al final de cada curso, sino como parte de los trámites de cada grado. E1 Reglamento correspondiente dedica todo su título $\mathrm{V}$ a normar las diferentes pruebas que deben sustentarse para la obtención de cada uno de los grados en cada una de las facultades y carreras (Lares, 1855: V. 188-240). Como parte de estas pruebas y para la obtención del grado de doctor, destaca el surgimiento de la "Memoria original e inédita sobre algún punto que importe algún adelanto en la ciencia" (Lares, 1855: V. 199). Sin duda, esta "memoria" da cima al moderno sistema educativo establecido en el Plan de estudios de 1854 y constituye, en buena medida, la primera formulación de nuestras modernas tesis de investigación. Es necesario aclarar que esta memoria se requería para los grados de doctor de las secciones de ciencias físico-matemáticas y ciencias naturales de la facultad de Filosofía; así como para las de medicina y farmacia (Lares, 1855: V. 199 y 214). El carácter científico de ambas carreras parece explicar esta novedad, pues una Memoria semejante no se solicita para los doctorados en la sección de literatura de la facultad de filosofía, ni para los de jurisprudencia ni teología. Para todos estos sigue demandándose una disertación oral, formulada con poco tiempo de antelación, esto es, una franca reminiscencia escolástica (Lares, 1855: V. 233).

\section{Conclusiones}

Llegados a este punto, podemos decir que el Plan de Estudios de 1854 y su Reglamento, de 1855, constituyen un punto culminante en la construcción del primer sistema educativo mexicano de la época contemporánea. Por primera vez, una ley educativa concebía un conjunto de instituciones educativas articuladas entre sí y organizadas a 
partir de criterios que establecían diferentes niveles de complejidad educativa.

En lo relativo a los grados académicos podemos concluir que se había operado el abandono del antiguo modelo escolástico, colonial, que les confería un significado docente y corporativo. La universidad no era más una institución que formaba exclusivamente catedráticos de las disciplinas que enseñaba. Había ampliado sus horizontes y sus graduados podían buscar acomodo en distintas alternativas profesionales.

Los grados académicos ahora certificaban la posesión de los conocimientos impartidos en las facultades, que había sido demostrada mediante la aprobación de diferentes exámenes. Es decir, todos los grados, desde el bachiller hasta el doctor, habían sido escolarizados. No podía ganarse uno sin haber asistido y aprobado los cursos correspondientes. También habían sido jerarquizados en función del avance en el nivel de conocimiento, por lo que no podía obtenerse uno sin contar con el anterior.

La introducción de los estudios preparatorios como un nivel propedéutico de las facultades y su certificación mediante el grado de bachiller excluyó a este grado, en buena medida, del ámbito universitario, pues aunque se mantuvo su existencia en las facultades, perdió importancia, debido a la decisión de hacer del grado de licenciado el que habilitaría para el ejercicio profesional.

El doctorado, por su parte, y en especial el relativo a las ciencias naturales, adquirió un carácter científico, al demandar la memoria de investigación, muy semejante entonces a nuestras actuales tesis doctorales.

El desarrollo de estas ideas se llevó a cabo en el lapso que va de 1824 a 1855 , pero no fue lineal o progresivo. La radical supresión de la universidad ocurrida en 1833 no logró articular el sistema educativo que formularía el ministro conservador Teodosio Lares. Ni la restauración universitaria de 1843 por parte de otro ministro conservador, Baranda, era una vuelta al pasado colonial o escolástico. Los grados académicos habían logrado subsistir transformándose radicalmente. Los universitarios del periodo colonial, a diferencia nuestra, difícilmente habrían podido reconocer como pares a los nuevos bachilleres, licenciados o doctores. El cambio académico experimentado daba lugar a un modelo educativo que bien podemos llamar "contemporáneo". 


\section{Referencias}

Alonso Romero, María Paz (1997), Universidad y sociedad corporativa. Historia del privilegio jurisdiccional del Estudio salmantino, Madrid, Editorial Tecnos.

Alvarado, María de Lourdes (2000), "La Universidad entre la tradición y el cambio. 1833", en Tradición y reforma en la universidad de México, México, CESU/ Miguel Ángel Porrúa.

Archivo General de la Nación, Ramo Universidad, vol. 5.

Baranda, Manuel (2011), "Plan General de Estudios de la República Mexicana, 1843", en La Reforma Educativa de Manuel Baranda. Documentos para su estudio (1842-1846) [transcripción y estudio de Rosalina Ríos y Cristian Rosas Íñiguez], México, IISUE, UNAM, pp. 27-39.

Becerra, José Luis (1963), La organización de los estudios en la Nueva España, México, Editorial Cultura.

Blasco Gil, Yolanda (2000), La facultad de derecho de Valencia durante la Restauración (1875-1900) [pról. de Mariano Peset], Valencia, Universitat de València.

Blasco Gil, Yolanda y María Fernanda Mancebo (2010), Oposiciones y concursos a cátedras de historia en la Universidad de Franco (1939-1950), Valencia, Universitat de València.

Cerralvo, Marqués de (1991), Proyecto de estatutos ordenados por el virrey Cerralvo (1626) [ed. de Enrique González], México, CESU, UNAM.

"Decreto. Facultad a todos los colegios para establecer cátedras de derecho natural, civil y canónico y conferir [menos los de México y Guadalajara] a sus respectivos alumnos todos los grados menores. México, 13 de octubre de 1823" (1825), en Colección de los decretos y órdenes del soberano congreso mexicano. Desde su instalación en 24 de febrero de 1822 hasta 30 de Octubre de 1823, en que cesó, México, Imprenta del Supremo Gobierno de los Estados Unidos Mexicanos, p. 209.

Farfán, Pedro (1951), "Estatutos de Esta real universidad por el doctor Farfán”, en Julio Jiménez
Rueda (ed.), Las constituciones de la antigua universidad, México, Facultad de Filosofía y Letras, UNAM, pp. 73-74.

Fernández del Castillo, Francisco (1953), La facultad de medicina según el archivo de la Real y Pontificia Universidad de México, México, Consejo de Humanidades, UNAM, p. 311.

Gómez Farías, Valentín (1834a), "Ley de 19 de octubre de 1833", en Leyes y reglamento para el arreglo de la Instrucción pública en el Distrito Federal, México, Imprenta de la Dirección de Instrucción Pública, pp. 5-11.

Gómez Farías, Valentín (1834b), "Ley de 23 de octubre de 1833", en Leyes y reglamento para el arreglo de la Instrucción pública en el Distrito Federal, pp. 11-23.

Gómez Farías, Valentín (1834c), "Reglamento General para sistemar la instrucción pública en el Distrito Federal", en Leyes y reglamento para el arreglo de la Instrucción pública en el Distrito Federal, pp. 53-126.

Gómez Farías, Valentín (1834d), "Ley de 23 de abril de 1834", en Leyes y reglamento para el arreglo de la Instrucción pública en el Distrito Federal, pp. 48-49.

Lanning, John Tate (1997), El Real Protomedicato. La reglamentación de la profesión médica en el Imperio español [trad. Miriam de los Ángeles Díaz Córdoba y José Luis Soberanes Fernández], México, UNAM.

Lares, Teodosio (1877), "Diciembre 19 de 1854. Decreto del gobierno. Plan general de Estudios", en Manuel Dublán y José María Lozano, Legislación Mexicana o colección completa de las disposiciones legislativas expedidas desde la independencia de la República, México, Imprenta del Comercio, vol. VII, pp. 344-369.

Lares, Teodosio (1855), Reglamento General de Estudios, México, Imprenta de Juan B. Navarro.

Leyes y Reglamento para el arreglo de la Instrucción Pública en el Distrito Federal (1834), México, Imprenta de la Dirección de Instrucción Pública, pp. 11-23.

Melgar Adalid, Mario (1995), “Teodosio Lares, 
encargado del despacho", en Anuario Mexicano de Historia del Derecho, México, núm. VII, pp. 103-124.

O'Gorman, Edmundo (2009), Justo Sierra y los origenes de la Universidad de México 1910, México, Instituto de Investigaciones Filosóficas-Programa de maestría y doctorado en Filosofía-UNAM.

Palafox y Mendoza, Juan de (1775), Constituciones de la Real y Pontificia Universidad de México, México, Imprenta de D. Felipe de Zúñiga y Ontiveros.

Pavón Romero, Armando (2010), El gremio docto. Organización corporativay gobierno dela Real Universidad de México en el siglo XVI, Valencia, Universidad de Valencia.

Peset, Mariano, Yolanda Blasco, Jorge Correa et al. (2000), Lecciones de historia del derecho, Valencia, Artes Gráficas Soler.

Peset, Mariano (2012), Obra dispersa. La universidad de México, México, IISUE, UNAM/ Ediciones y Cultura. Ramírez González, Clara Inés (2001), Grupos de poder clerical en las universidades hispánicas. Los regulares en Salamanca y México durante el siglo XVI, México, CESU, UNAM.
Rashdall, Hastings (1997), The universities of Europe in the middle agges, Somerset, Oxford University Press.

"Real pragmática", en Francisco Fernández del Castillo, La facultad de medicina según el archivo de la real y Pontificia Universidad de México, México, Consejo de Humanidades, UNAM, 1953 (Ediciones del IV Centenario de la Universidad de México, XIV), pp. 115-123.

Ríos, Rosalina (2001), "La creación de un plan de estudios moderno en el Instituto Literario de Zacatecas (1832-1854)", en Margarita Menegus, Universidad y sociedad en Hispanoamérica: grupos de poder siglos XVIII $y$ XIX, México, CESU, UNAM, pp. 355-383.

Rodríguez-San Pedro Bezares, Luis Enrique (1986), La universidad salmantina del barroco, periodo 15981625, Salamanca, Ediciones Universidad de Salamanca.

Verger, Jacques (1994), "Profesores", en Historia de la Universidad en Europa. Volumen I. Las universidades de la Edad Media [ed. por Hilde de Ridder-Symoens], Bilbao, Servicio editorial Universidad del País Vasco, pp. 163-191.

\section{Cómo citar este artículo:}

Pavón-Romero, Armando, Yolanda Blasco-Gil y Luis-Enrique Aragón-Mijangos (2013), "Cambio académico. Los grados universitarios. De la escolástica a los primeros ensayos decimonónicos", en Revista Iberoamericana de Educación Superior (RIES), México, UNAM-IISUE/Universia, vol. IV, núm. 11, pp. 61-81, http://ries.universia.net/ index.php/ries/article/view/383 [consulta: fecha de última consulta]. 